\title{
Reflexiones sobre la trayectoria de Enrique Romero Brest: un profesional al servicio del Estado (primeras décadas del siglo XX)
}

\author{
Stella M. Cornelis*
}

Fecha de Recepción: 31 de julio de 2021

Fecha de Aceptación: 5 de octubre de 2021

DOI: https://doi.org/10.46553/RGES.57.2021.p.112-135

\section{Resumen}

En el artículo se indaga sobre el perfil y la trayectoria de Enrique Romero Brest, un referente clave en la conformación del campo disciplinar de la educación física escolar. En este sentido, nos interrogamos sobre su formación, los vínculos que entabló, su ingreso a las filas de las elites estatales y la labor desarrollada, que lo llevaron a convertirse en un profesional e intelectual al servicio del Estado. La producción de conocimientos que desarrolló en el Instituto Superior de Educación Física y su difusión en diversas publicaciones, lo convirtieron en un especialista y por tanto en una autoridad legítima de ese campo disciplinar. Al mismo tiempo generó saberes de Estado que tenían como propósitos contribuir al perfeccionamiento físico y la salud corporal de los individuos que formaban el porvenir del país.

Palabras clave: Educación física; Profesional; Intelectual; Saberes de Estado.

\begin{abstract}
In the article we enquire about the profile and trajectory of Enrique Romero Brest, a key reference in the conformation of the disciplinary field of school physical education. In this way, we question about his formation, the links he established, his entrance in the rows of the Estate and the work developed, which turn him into a professional and intellectual to the service of the Estate. The production of knowledge that he developed in the Instituto Superior de Educación Física and the diffusion in various publications, they turn him into a specialist and therefore into a legitimate authority of this disciplinary field. At the same time he generated knowledge of Estate which had as a purpose the contribution to the physical perfectionism and body health of the individuals who formed the future of the country.
\end{abstract}

Keywords: Physical education; Professional; Intellectual; Estate’s knowledge.

\section{Introducción}

Enrique Romero Brest fue un referente clave en la conformación del campo disciplinar de la educación física escolar. Sus estudios y reflexiones lo llevaron a idear un sistema racional y científico, sustentado en los pilares de la fisiología, la higiene y la pedagogía, que mantuvo supremacía en el campo de la disciplina hasta fines de los años '30. ${ }^{1}$ La tesis que

\footnotetext{
* Instituto de Estudios Socio Históricos, Facultad de Ciencias Humanas-Universidad Nacional de La Pampa, stellacornelis@yahoo.com.ar

${ }^{1}$ Ángela Aisenstein, "Cuerpo, escuela y pedagogía. Argentina siglos XIX y XX", en Tras las huellas de la Educación Física Escolar Argentina. Cuerpo, género y pedagogía 1880-1950. Aisenstein, Ángela y
} 
elaboró para graduarse de médico -enfocada en el estudio del ejercicio físico escolar desde el punto de vista higiénico-, su formación posterior y los vínculos profesionales que construyó le permitieron convertirse en una autoridad científica indiscutida a la hora de definir los contenidos para esa asignatura. Así, fue respetado y reconocido tanto por los médicos como por los pedagogos.

$\mathrm{Su}$ figura ha interpelado a diversos investigadores, que se enfocaron en cuestiones específicas de su obra, como el sistema de educación física o la política corporal generizada. ${ }^{2}$ Sin embargo, ninguno de esos estudios se enmarcó teóricamente en los abordajes que examinan los intelectuales y profesionales de Estado; ${ }^{3}$ este trabajo espera contribuir en ese sentido. La propuesta del artículo es analizar el perfil de Romero Brest y su posterior trayectoria, que lo llevaron a convertirse en un profesional al servicio del Estado. ${ }^{4}$

Nos centraremos en los saberes y prácticas comprometidas con su actividad, y en la producción de conocimiento en ese campo disciplinar. Los maestros y profesores no han sido suficientemente descriptos por las investigaciones sociales como encarnación de la figura del intelectual; tal vez esta desatención esté vinculada con su subordinación a otros profesionales que ocuparon las esferas estatales y definieron las políticas educativas, como fueron los médicos y abogados. ${ }^{5}$ Si bien Romero Brest se desempeñó como docente fue, sin lugar a dudas, su titulación en medicina la que lo habilitó para ocupar puestos en el Estado.

Scharagrodsky, Pablo (Buenos Aires: Prometeo, 2006), pp. 19-48; Pablo Scharagrodsky, "El padre de la educación física argentina: fabricando una política corporal generizada (1901-1938)", en Tras las huellas de la Educación Física Escolar Argentina. Cuerpo, género y pedagogía 1880-1950, Aisenstein, Ángela y Scharagrodsky, Pablo (Buenos Aires: Prometeo, 2006), pp. 159-197.

${ }^{2}$ Pablo Scharagrodsky, "El padre de..., Abel Agüero, Silvia Iglesias y Ana Del Valle Milanino. "Enrique Romero Brest y los inicios de la Educación física escolar. Su tiempo, su vida, su pensamiento y su obra", eä Journal, Vol. 1, № 1, (2009): pp. 1-38, http://www.ea-journal.com/art/Enrique-Romero-Brest.pdf; Eduardo Galak, "Educación del cuerpo y política: concepciones de raza, higienismo y eugenesia en la Educación Física Argentina", Movimiento. Vol. 20, $\mathrm{N}^{\circ} 2$ (2014): pp. 1543-1562, https://seer.ufrgs.br/Movimento/article/view/46138/32491.

${ }^{3}$ Magali Safartti Larson. "Acerca de los expertos y los profesionales o la imposibilidad de haberlo dicho todo", Revista de Educación, No Extra 1, (1989): pp. 199-237; Mariano Plotkin y Federico Neiburg (comp.). Intelectuales y expertos. La constitución del conocimiento social en la Argentina, (Buenos Aires: Paidós, 2004): pp. 15 a 30 .

${ }^{4}$ Magali Safartti Larson. “Acerca de...; Ernesto Bohoslavsky y Germán Soprano. Un Estado con rostro humano. Funcionarios e instituciones estatales en Argentina (desde 1880 a la actualidad) (Buenos Aires: Prometeo, 2010); Laura Graciela Rodríguez y Germán Soprano (editores). Profesionales e intelectuales de Estado. Análisis de perfiles y trayectorias en la salud pública, la educación y las fuerzas armadas (Rosario: Prohistoria, 2018).

${ }^{5}$ Ricardo González Leandri. "La elite profesional docente como fracción intelectual subordinada. Argentina: 1852-1900”, en Anuario de Estudios Americanos, Vol. 58, ํo2, (2001): pp. 513-535, http://estudiosamericanos.revistas.csic.es/index.php/estudiosamericanos/article/view/214/218; Lucía Lionetti. La misión política de la escuela pública. Formar a los ciudadanos de la república (1870-1916), (Buenos Aires: Miño y Dávila, 2007); Flavia Fiorucci y Laura Graciela Rodríguez. Intelectuales de la educación y el Estado: maestros, médicos y arquitectos, (Buenos Aires: Universidad Nacional de Quilmes, 2018; Laura Graciela Rodríguez y Germán Soprano. Profesionales e intelectuales... 
En primer lugar reconstruiremos su itinerario formativo y la trayectoria profesional, en este sentido nos interrogamos sobre su formación y especialización en el campo de la educación física, su ingreso a las filas de las elites estatales y la labor que desarrolló en ese contexto. Luego, examinaremos cuáles fueron los saberes de Estado que produjo y que nos permiten estudiar su perfil como un profesional e intelectual. Finalmente, nos preguntamos por el valor social de esos conocimientos.

\section{Perfil y trayectoria profesional de Enrique Romero Brest}

Nació en Goya, provincia de Corrientes, el 25 de septiembre de 1873. Realizó sus estudios secundarios en el Colegio Nacional de Corrientes, institución que era dirigida en ese momento por Santiago Fitz Simon. ${ }^{6}$ En 1892 comenzó la carrera de medicina en la Universidad de Buenos Aires; se graduó en 1900 al aprobar una tesis enfocada en el estudio del ejercicio físico escolar desde el punto de vista higiénico. ${ }^{7}$ Algunos de los temas que abordó en esa obra inicial fueron la fisiología del ejercicio, los objetivos de la educación física y las condiciones médico pedagógicas necesarias para llevarla a cabo. En ese documento se mostró como un firme seguidor de las orientaciones positivistas en lo biomédico, defensor de las ideas eugenésicas desde el punto de vista médico-social y arguyó que el "deber ser" de la educación física escolar era la "conservación de la salud y el desarrollo armónico del organismo". 8 Consideraba que el mejor sistema de ejercicios físicos para la escuela eran las prácticas y juegos metodizados al aire libre, alternados con ejercicios gimnásticos y dirigidos por personal competente. En ese sentido, se interrogó sobre la posibilidad de que fueran los galenos, ante la ausencia de docentes capacitados, quienes efectuaran esa supervisión. ${ }^{9}$

Mientras realizaba sus estudios de medicina se relacionó con reconocidos educadores, como Pablo Pizzurno y Gerardo Victorín. Su vínculo con ellos surgió cuando fue designado

\footnotetext{
${ }^{6}$ Educador inglés, contratado por el gobierno argentino para organizar la instrucción de las escuelas secundarias.

${ }^{7}$ No fue el primer médico interesado en ese tópico. Antes que él otros médicos se preocuparon por la gimnasia y la ejercitación y le otorgaron valor a sus prácticas para la prevención de enfermedades. Un estudio sobre los planteos y posicionamientos de diversos galenos respecto de la educación física puede consultarse en Pablo Scharagrodsky "Entre la maternidad y la histeria. Medicina, prácticas corporales y feminidad en el Buenos Aires a fin de siglo XIX", en Gobernar es ejercitar. Fragmentos históricos de la Educación Física en Iberoamérica, compilado por Scharagrodsky, Pablo (Buenos Aires: Prometeo, 2008), pp. 105-135; Pablo Scharagrodsky. "La constitución de la educación física escolar en la Argentina. Tensiones, conflictos y disputas con la matriz militar en las primeras décadas del siglo XX", en La invención del "homo gymnasticus". Fragmentos históricos sobre educación de los cuerpos en movimiento en Occidente, compilado por Scharagrodsky, Pablo (Buenos Aires: Prometeo, 2011), pp. 441-475.

${ }^{8}$ Enrique Romero Brest. El ejercicio físico en la escuela (del punto de vista higiénico). Contribución al estudio de esta cuestión para nuestras escuelas, (Buenos Aires: Compañía Sud-Americana de Billetes de Banco, 1900), p.19.

9 Abel Agüero, Silvia Iglesias y Ana Del Valle Milanino. "Enrique Romero...
} 
ayudante en la asignatura de Trabajo Manual, que se dictaba en el Instituto Nacional de Caballito. ${ }^{10}$ Conformaron un "triunvirato", mediante el cual estrecharon lazos laborales y amicales. ${ }^{11}$ Presuponemos que esa relación fue fundamental para su posicionamiento en el ámbito del Estado; en 1898 Pizzurno fue designado Inspector General de Enseñanza Secundaria y Normal y propuso una reforma para la educación física. En ese contexto Romero Brest fue convocado para integrar la Comisión Profesional de Médicos constituida a instancias de Osvaldo Magnasco, Ministro de Justicia e Instrucción Pública, cuyo propósito fue establecer las reglas de una gimnasia científica. No solamente fueron esas redes que había construido las que favorecieron su inserción en el Estado; también los saberes que acreditaban su conocimiento y la expertise que paulatinamente adquirió a partir de su experiencia profesional. Así, elaboró la reglamentación que reorganizó esa materia en los colegios nacionales y fue designado en 1901 para dictar y dirigir los cursos temporarios de capacitación docente. $^{12}$

Romero Brest percibía que en el mundo se estaban produciendo cambios respecto de la instrucción corporal en las escuelas. Además, rescató las voces de inspectores, rectores de colegios nacionales y pedagogos, que clamaron por introducir transformaciones en la enseñanza de la asignatura. Ello lo llevó a proponer la introducción del curso de educación física a las escuelas normales, en el 4 y 5 año de estudios. Del mismo modo sugirió incorporar un trayecto de similar en la Facultad de Filosofía y Letras para enseñar anatomía, fisiología e higiene aplicada a la educación física (que debía ser obligatorio para inspectores, directores y regentes de escuelas). Finalmente, su proyecto buscó establecer cursos teóricos-prácticos transitorios para maestros de escuelas primarias del país y reformar los programas de las escuelas normales. $^{13}$

También advertimos su impronta en el decreto aprobado en 1905, que trazó los lineamientos de un "Plan de enseñanza y de educación física nacional", ya que en el origen de esa normativa identificamos un proyecto que Leopoldo Lugones había solicitado a Romero

\footnotetext{
${ }^{10}$ Esta institución fue fundada por Pizzurno; allí trató de implementar los métodos modernos de educación que había conocido al viajar a Europa. Consultar Jorge Saraví Rivière. Historia de la educación física en Argentina (Buenos Aries: Libros del Zorzal, 2012), pp. 187-188.

${ }^{11}$ Esos vínculos quedaron plasmados en un copioso epistolario intercambiado entre Pizzurno y Romero Brest; consultar Ricardo Rodríguez Pereyra y Martín Pereyra. Correspondencia. Pablo A. Pizzurno - Enrique Romero Brest 1895-1911. Primera Parte, Buenos Aires: Centro de Documentación Histórica y Museo de la Educación Física y el Deporte, s/f. También Pizzurno manifestó sobre los lazos de amistad que lo unían a Romero Brest en varias oportunidades y se auto culpó por influenciarlo en su decisión de dejar su especialización como cirujano. Véase al respecto Pablo Pizzurno. "El Instituto Superior Nacional de Educación Física", en El Monitor de la Educación Común, Año 33, Tomo 52, № 504 (1914), pp. 399-414.

${ }^{12}$ Consultar Enrique Romero Brest. Cursos Normales de Educación Física (sus resultados) (Buenos Aires: Librería y casa Editora de Nicolás Marana, 1903).

${ }^{13}$ Enrique Romero Brest. Cursos Normales..., pp. 11-12.
} 
Brest. Ese reglamento, para escuelas normales y colegios nacionales, establecía la obligatoriedad de la asignatura y una propuesta de capacitación a desarrollarse en dos años. De esa manera, se establecieron los cursos normales con un carácter permanente. Esa fue la base de lo que luego sería la Escuela de Educación Física. Contar con planes y programas no garantizaba la implementación de una gimnasia racional, se corría el riesgo de que quedaran en "letra muerta" si los encargados de interpretarla y aplicarla no estaban preparados para ello. ${ }^{14}$ Esta fue otra preocupación que lo desveló: la formación de personal competente, es decir docentes calificados.

A medida que la educación corporal iba jerarquizándose al interior del sistema educativo se configuró una dependencia con el objetivo de vigilar y controlar esas prácticas. ${ }^{15}$ Así, Romero Brest fue designado al frente de la Inspección de Educación Física del Consejo Nacional de Educación, cargo que desempeñó entre 1904 y 1909. El primer informe que elaboró en calidad de Inspector fue muy crítico respecto de la enseñanza de la gimnasia; argumentó que las clases eran consideradas un pasatiempo aburrido, con efectos contrarios a los que se esperaba de esas prácticas, la carga horaria era insuficiente y los edificios deficientes, entre otras problemáticas que advirtió. Recomendó una serie de modificaciones para terminar con ese panorama desalentador, entre ellas propuso efectuar concursos. ${ }^{16}$ Con ellos buscó cautivar a los niños, motivarlos en su perfeccionamiento físico y, en paralelo, exteriorizar los esfuerzos de los maestros y demostrar los resultados obtenidos. ${ }^{17}$ También elevó en 1907 un informe al Inspector General de Enseñanza Secundaria y Normal con propuestas para mejorar la instrucción de la cultura física en las escuelas normales y evitar que se militarice su enseñanza. Entre los puntos propuestos en ese proyecto destacamos la calificación mensual de los estudiantes -medida necesaria para que concurrieran periódicamente a clase y pudieran aprovechar los beneficios de la gimnasia-, la realización de

\footnotetext{
${ }^{14}$ Enrique Romero Brest. Cursos Normales..., p. 51.

${ }^{15}$ La Inspección no tuvo una existencia extendida en el tiempo ya que fue suprimida por José María Ramos Mejía y el Inspector General Ernesto Bavio. Enrique Romero Brest. "Organización de la Educación Física en la Argentina", Boletín del Instituto Internacional Americano de Protección a la Infancia. Tomo IV, № 1, (1930), p. 9. Durante la gestión de Ramos Mejía también se suprimieron los cursos temporarios de ejercicios físicos para maestros y los concursos de estudiantes. Los argumentos pueden consultarse en Ernesto A. Bavio. "Dictámenes", El Monitor de la Educación Común, Año XXVIII, Tomo XXIX, No 438, (1909), pp. 457-468.

${ }^{16}$ Consultar el informe completo en Enrique Romero Brest. "Informe. Sobre las condiciones actuales de la educación física en nuestras escuelas", El Monitor de la Educación Común, Año XXV, Tomo XX, № 382, (1904), pp. 83-96.

${ }^{17}$ Enrique Romero Brest. “Organización del concurso de Educación física”, El Monitor de la Educación Común, Año XXV, Tomo XXI, No 391, (1905), pp. 92-93. Asimismo, pueden consultarse el Informe sobre el primer concurso de Educación Física, elevado por Enrique Romero Brest y publicado en El Monitor de la Educación Común, Año XXV, Tomo XXI, No 395, (1905), pp. 487-520 y Enrique Romero Brest. "4º Concurso General de Educación física", El Monitor de la Educación Común, Año XXVIII, Tomo XXVII, N 432, (1908), pp. 989994.
} 
excursiones, la instrucción de tiro al blanco para los varones de los dos últimos años centrada en los ejercicios simples que requería el manejo correcto del arma de guerra, ${ }^{18}$ la prohibición de designar profesores no diplomados, entre otros puntos. ${ }^{19}$

Al formar parte de esa agencia estatal tuvo injerencia en la modificación de los planes y programas vigentes sobre enseñanza de la educación física y por lo tanto en la definición de los contenidos a enseñar. ${ }^{20}$ De esa manera, adquirió un capital simbólico que lo posicionó como referente incuestionable en la materia. Ese recorrido previo validó su designación como docente y director de la Escuela Normal de educación física, devenida hacia 1912 en Instituto Superior de Educación Física. ${ }^{21}$ Logró el reconocimiento de sus colegas, en tanto lo definían como el "primer especialista en el ramo" 22 y, por lo tanto, una autoridad indiscutida en los campos de la medicina y la pedagogía. ${ }^{23}$

Un hito importante en su carrera profesional fue la asistencia al Congreso Internacional de Educación Física que se realizó en París. ${ }^{24}$ Fue designado representante del gobierno Argentino; allí participaron figuras de renombre internacional y se abordaron temáticas sobre la fisiología del ejercicio, cinesiterapia, la educación física escolar y la preparación militar, equitación, tiro y sport de combate, entre otros tópicos. ${ }^{25}$ Ese viaje le

\footnotetext{
${ }^{18}$ Estas prácticas estarían a cargo de oficiales del Ministerio de Guerra, especialmente instructores de tiro, designados para ese fin. Además, debían realizar las actividades físicas habituales.

${ }^{19}$ Enrique Romero Brest. "La reforma de la educación física en la escuela secundaria", El Monitor de la Educación Común, Año XXVIII, Tomo XXV, № 419, (1907), pp. 348-362.

${ }^{20}$ Pablo Scharagrodsky, "El padre de...; Pablo Scharagrodsky. "La constitución...

${ }^{21}$ Un decreto del Ministro Rómulo S. Naón convirtió el curso normal en Escuela Normal de Educación Física. En 1912 se jerarquizó esa institución elevándola al rango de Instituto Superior de Educación Física. Consultar Jorge Saraví Rivière. Historia de la ..., p. 211.

${ }^{22}$ Leopoldo Lugones. Didáctica. (Buenos Aires: Otero \& Cía. Impresores, 1910), p. 8.

${ }^{23}$ En 1914 fue nombrado director de la Confederación Nacional del Magisterio y desde esa tribuna clamó por los derechos de los maestros. Consultar la nota Consejo Nacional de Educación. "La Confederación del magisterio", en El Monitor de la Educación Común, Año XXXII, N 495, Tomo XLVIII, (1914), pp. 268-269 y Enrique Romero Brest. Discursos pronunciados por el Director General de la Confederación Nacional del Magisterio, (Buenos Aires: Casa Editora, Librería e imprenta Europea de M. A. Rosas, 1914).

${ }^{24}$ El programa del congreso puede consultarse en Enrique Romero Brest. La educación física Argentina. Congreso Internacional de París, (Buenos Aires: Librería e Imprenta Europea, 1913), pp. 46-50. A partir de ese evento se constituyó una Comisión Técnica Internacional permanente de Educación Física -reunió dieciséis miembros de países europeos y de América del Sur-, que coordinó varios congresos sobre la temática y favoreció la creación del Instituto Internacional de Educación Física en 1911. El mismo se convirtió en un espacio de organización y comunicación internacional sobre los aspectos relacionados con la educación física; Carvalho, Luis Miguel. "Circulación internacional de saberes, desplazamientos semánticos y alineaciones políticas: a propósito de las disputas sobre la Gimnasia de Ling en Portugal, en los años veinte y treinta del siglo XX", en $L a$ invención del homo gymnasticus. Fragmentos históricos sobre educación de los cuerpos en movimiento en Occidente, compilado por Scharagrodsky, Pablo (Buenos Aires: Prometeo, 2011), pp. 225-250.

${ }^{25}$ Varios pedagogos argentinos viajaron a Europa en años previos y allí conocieron a exponentes del campo de la cultura física; entre ellos podemos mencionar a Pablo Pizzurno, José Benjamín Zubiaur, Juan G. Beltrán, Enrique Romero Brest. Consultar Pablo Scharagrodsky y Jacques Gleyse. "El Dr. Enrique Romero Brest, las visitas a instituciones europeas de formación y el Congreso de Educación Física realizado en 1913 como indicadores de la globalización y la nacionalización de la cultura física", Staps, 2013/2, № 100, (2013): pp. 89107, https://www.cairn.info/revue-staps-2013-2-page-89.htm.
} 
permitió a Enrique Romero Brest impregnarse de conocimientos y saberes relacionados con los principios que orientaban la enseñanza de la asignatura en las escuelas europeas. En su visita a diversas instituciones educativas analizó desde sus planes y programas de estudio, los métodos de enseñanza y sistemas utilizados, los materiales didácticos, hasta la arquitectura de los establecimientos. ${ }^{26}$ Sin lugar a dudas, esos contactos internacionales y los conocimientos que allí adquirió, afianzaron su posicionamiento como profesional al servicio del Estado. A partir de la asistencia a ese evento la propuesta de Romero Brest obtuvo mayor legitimidad frente a los grupos que disputaban el control de la educación corporal en las instituciones argentinas. $^{27}$

Fue muy prolífera su labor al frente del Instituto, allí formó a docentes y difundió saberes y prácticas relacionados con esa disciplina escolar, alentó la organización de clubes atléticos en colegios nacionales, creó en 1909 -con otros colaboradores- la Asociación de Profesores de Educación Física. Sus miembros buscaron posicionarse como los únicos referentes autorizados para definir los lineamientos de una educación física escolar, organizada científicamente según los parámetros del discurso médico. Reclamaron reiteradamente a las autoridades del Ministerio de Justicia e Instrucción Pública ante el

\footnotetext{
${ }^{26}$ En el año 1913 visitó lugares como la Escuela Normal de Educación Física de Bruselas, los Institutos Reales de Educación Física para el Magisterio de Roma, Torino y Nápoles, también estuvo en el Instituto Superior de Copenhague, en el Instituto Central de Estocolmo, en el Curso Superior de Educación Física de París y en la Escuela Normal de Gimnasia y Esgrima de Joinville le Pont. Además, tuvo la oportunidad de visitar clases de educación física en algunas escuelas modelos primarias en Bruselas y otras semejantes en Estocolmo, así como en L'École des Rochesde Verneuil. Véase Enrique Romero Brest. La educación fisica ... y Pablo Scharagrodsky y Jacques Gleyse. "El Dr. Enrique...

${ }^{27}$ Cabe aclarar que en la matriz constitutiva de esta disciplina escolar se delinearon tensiones entre dos posturas: unos identificaron gimnasia con ejercicios militares y otros pedían la sustitución de ese tipo de prácticas por una educación física científica-racional y por juegos al aire libre. De esta manera, en los comienzos de su constitución dejaron su impronta muchos militares. En 1897 se creó la Escuela de Gimnasia y Esgrima del Ejército; varios de sus maestros, y luego los egresados, tuvieron una actuación destacada en la educación física escolar, ya que mediante un decreto del Poder Ejecutivo fueron autorizados a dictar clases en el sistema educativo. Este vínculo entre gimnasia escolar y militares se reforzó a fines del siglo XIX apoyado en un imaginario que asociaba la preparación militar con la formación de la nacionalidad y los valores patrióticos. Los batallones escolares que surgieron en ese contexto fueron un claro ejemplo de esa época. Esta tensión entre pedagogos y militares, respecto de la definición de los contenidos de la educación física, resurgirá en contextos en los que las fuerzas armadas tengan mayor presencia en el gobierno como ocurrirá a partir de los años ' 30 . Consultar Cristiani, Roberto J. Reseña histórica del cuerpo de Gimnasia y Esgrima del Ejército y su proyección en la vida nacional. Algunos aspectos de su evolución entre 1897-1960 (Comando en Jefe del Ejército, Buenos Aires: Dirección de Estudios Históricos, 1967); Bertoni, Lilia Ana. Patriotas, cosmopolitas y nacionalistas. La construcción de la nacionalidad argentina a fines del siglo XIX (Buenos Aires: Fondo de Cultura Económica, 2001); Pablo Scharagrodsky. "Los ejercicios militares en la Escuela Argentina: modelando cuerpos masculinos y patriotas a fines del siglo XIX", en Tras las huellas de la Educación Física Escolar Argentina. Cuerpo, género y pedagogía 1880-1950, Aisenstein, Ángela y Scharagrodsky, Pablo (Buenos Aires: Prometeo, 2006), pp. 105133; Levoratti, Alejo. "La gimnasia o la esgrima. Análisis de la formación e incorporación de los maestros de gimnasia y esgrima en el Ejército Argentino y en la Educación Física (1897-1934)", en Profesionales e intelectuales de Estado. Análisis de perfiles y trayectorias en la salud pública, la educación y las fuerzas armadas, editado por Rodríguez, Laura Graciela y Soprano, Germán (Rosario: Prohistoria, 2018), pp. 121-140.
} 
incumplimiento de designar profesores de la materia; de esa forma defendían a los docentes con título otorgado por el Instituto. ${ }^{28}$

Aunando, por un lado, su formación en medicina y, por el otro, sus experiencias en la enseñanza, investigó temáticas relacionadas con la antropometría, buscó medir las características morfo-funcionales del cuerpo humano y en ese proceso inventó aparatos que permitían realizar mediciones corporales. ${ }^{29}$ Una de las materias que dictó en el Instituto Nacional de Educación Física era físiología; como los contenidos teóricos de esa asignatura debían plasmarse empíricamente, Romero Brest se abocó a la conformación de un Laboratorio de Fisiología. En este sentido, sus saberes estuvieron influenciados por académicos destacados en los estudios sobre el cuerpo en movimiento. ${ }^{30}$

En los años '20 formó parte de la Comisión Técnica de Educación Física, que se conformó con el objetivo de asesorar al gobierno sobre los métodos y procedimientos más adecuados para su enseñanza, la creación de estadios y plazas de deporte y la elaboración de una "legislación conveniente para el desenvolvimiento de la educación física". 31 Los integrantes de este organismo elaboraron un ante-proyecto de ley orgánica, que resguardó el sistema argentino de educación física para el ámbito escolar, rechazó la militarización de su enseñanza en las instituciones educativas, recomendó una mayor presencia de los deportes y garantizó la preponderancia del Instituto de Educación Física como institución formadora de

\footnotetext{
${ }^{28}$ Sobre el accionar de esta Asociación consultar Saraví Rivière. Historia de la... y Pablo Scharagrodsky. "Cartografiando acciones, significados y disputas en el campo de la cultura física argentina. El caso de la Asociación de Profesores de Educación Física”, en XIV Jornadas Interescuelas/Departamentos de Historia (Mendoza: Departamento de Historia, Facultad de Filosofía y Letras-UNCUYO 2013), http://cdsa.aacademica.org/000-010/911.pdf. La Asociación editó una revista denominada Fortitudo, entre los años 1921-1922; fue un espacio desde el cual un grupo de profesores comenzó a cuestionar los planteos de Romero Brest. Véase Ángela Aisenstein. "Tensiones en el discurso de la Educación Física: definiciones en la prensa pedagógica, Argentina, 1900-1940”, en Gobernar es ejercitar. Fragmentos históricos de la Educación Física en Iberoamérica, compilado por Scharagrodsky, Pablo (Buenos Aires: Prometeo, 2008), pp. 65-74 y Pablo Scharagrodsky. "Cartografiando acciones...

29 Entre sus invenciones destacamos el cirtómetro torácico de resorte, el espirómetro hidrostático, el dinamómetro de ancho adaptable a la mano, el kinetómetro torácico (permitía medir el diámetro y la circunferencia del tórax), el antropómetro milimétrico de precisión y el saltómetro doble invariable. Consultar Saraví Rivière. Historia de la..., Eduardo Galak. Del dicho al hecho (y viceversa). El largo trecho de la construcción del campo de la formación profesional de la educación física en Argentina. Legalidades, legitimidades, discursos y prácticas en la institucionalización de su oficio entre finales del siglo XIX y el primer tercio del siglo XX, (Buenos Aires: Facultad de Humanidades y Ciencias de la Educación, UNLP, 2012), http://sedici.unlp.edu.ar/bitstream/handle/10915/30971/Documento_completo__.pdf?sequence=1.

${ }^{30}$ Entre los principales referentes podemos mencionar a Étienne Jules Marey, Georges Demenij, Philippe Tissie, Ángelo Mosso y Fernand Lagrange. Sobre esta influencia y la transmisión de esos conocimientos en los cursos dictados consultar Pablo Scharagrodsky y Jacques Gleyse. "El Dr. Enrique... y Pablo Scharagrodsky. "El discurso médico y su relación con la invención del oficio de 'educador físico': entre la heteronomía solapada y la autonomía vigilada (Argentina, 1901-1931)”, en Miradas médicas sobre la cultura física en Argentina. 18801970, compilado por Pablo Scharagrodsky, (Buenos Aires: Prometeo, 2014), pp. 101-148.

${ }^{31}$ Consultar los objetivos, la letra del ante-proyecto y la nómina de integrantes de la Comisión en Ministerio de Justicia e Instrucción Pública. Despacho de la Comisión Técnica de Educación Física, (Buenos Aires: Talleres Gráficos Morenza Rañó 1924), p. 3.
} 
profesores a desempeñarse en las escuelas. ${ }^{32}$ No obstante, el proyecto no fue tratado por los legisladores y fue archivado. ${ }^{33}$

A lo largo de su trayectoria realizó innumerables investigaciones y produjo conocimientos que luego fueron divulgados en medios de prensa nacionales, en El Monitor de la Educación Común y en publicaciones internacionales como el Boletín del Instituto Internacional Americano de Protección a la Infancia; fue autor de diversos libros. Además, para difundir esa producción científica fundó la Revista Educación Física, publicación oficial del Instituto Superior de Educación Física. ${ }^{34}$ También dictó conferencias, entre otras actividades. Durante las tres primeras décadas del siglo XX su accionar fue vertebral en la conformación de los lineamientos curriculares, los planes de estudio y programas de las asignaturas para la formación de profesionales de educación física en Argentina. ${ }^{35}$ Desde los cursos temporarios que comenzaron a dictarse en 1901, pasando por la constitución del Instituto Superior de Educación física, y hasta la década de 1930, Romero Brest preparó científica y profesionalmente a diversas promociones de docentes. El Instituto fue la única institución en el país que se dedicó a la formación de profesores de educación física hasta $1939 . .^{36}$

Como experto y profesional de Estado produjo una serie de conocimientos y con ellos buscó intervenir en la sociedad; en este sentido, nos preguntamos qué saberes generó, cuáles fueron sus preocupaciones a la hora de elaborarlos, qué valores sociales poseyeron en ese momento y cuáles fueron las estrategias para implementarlos.

\section{Un sistema de enseñanza pensado para la Argentina}

\footnotetext{
${ }^{32}$ Pablo Scharagrodsky. "La constitución...; Pablo Scharagrodsky. El discurso médico... y Alejo Levoratti. "El deporte en la formación de los profesores normales de Educación Física en Argentina (1912-1940)", Revista Teoría e Práctica da Educação. V. 18, № 1, (2015), https://doi.org/10.4025/tpe.v18i1.29006.

${ }^{33}$ Enrique Romero Brest. Bases de la Educación física en la Argentina, (Buenos Aires: Librería del Colegio, 1939), p. 41.

34 Esta revista surgió con el propósito de publicar trabajos sobre fisiología, psicología y pedagogía de la educación física. Es posible identificar tres momentos en su publicación: entre 1900 y 1916, desde 1921 hasta 1931 y en el año 1936. Un análisis sobre la revista puede consultarse en Ángela Aisenstein. "Huellas de un doble alumbramiento. Historia de la asignatura y la ciencia en las páginas de la Revista de Educación Física”, en Tras las huellas de la Educación Física Escolar Argentina. Cuerpo, género y pedagogía 1880-1950. Aisenstein, Ángela y Scharagrodsky, Pablo, (Buenos Aires: Prometeo, 2006), pp. 73-101 y Ángela Aisenstein. Tensiones en el discurso...

${ }^{35}$ Pablo Scharagrodsky. El discurso médico... y Scharagrodsky, Pablo. La constitución de...

${ }^{36}$ En 1938 se creó la Dirección General de Educación Física y el Instituto de Educación Física quedó bajo su órbita, reformulándose su plan de estudios. En paralelo a estos cambios en 1939 se derogó el sistema argentino de educación física y se creó el Instituto General Belgrano en San Fernando. Consultar Alejo Levoratti. "La creación de los profesorados de educación física en Argentina. 1912-2014", en $11^{\circ}$ Congreso Argentino de Educación Física y Ciencias, (2015), http://www.memoria.fahce.unlp.edu.ar/trab_eventos/ev.7372/ev.7372.pdf.
} 
Sin lugar a dudas una de las creaciones intelectuales más importantes de Romero Brest fue el sistema argentino de educación física. En los informes presentados luego de dictar los cursos normales renegó sobre la ausencia de orientaciones comunes en la enseñanza; en sus críticas manifestó que cada "maestro enseña y hace lo que mejor le parece, sujetándose solo en apariencia a los programas oficiales". 37 Ello lo llevó a pergeñar un cuerpo de saberes que luego marcarían los rumbos a seguir. Este sistema de enseñanza, se consolidó a finales del primer decenio del siglo XX y, más allá de las críticas que comenzó a recibir durante los años '20, sus fundamentos se fortalecieron y tuvieron continuidad hasta fines de la década de $1930 . .^{38}$

Su punto de partida fueron los cuestionamientos a las escuelas gimnásticas europeas. Desaprobó la gimnasia francesa porque tendía a desarrollar la fuerza e hipertrofia de las masas musculares y sobre todo por su origen castrense. ${ }^{39}$ Esas pruebas físicas acortaban los músculos, encorvaban la espalda y por ese motivo terminaban siendo anti-fisiológicas, congestivas, anti-respiratorias, deformantes, entre otras características negativas. ${ }^{40}$ En contraposición, consideró que la gimnasia sueca se adaptaba mucho mejor a las necesidades anatómicas y fisiológicas de quienes la practicaban. El problema de ese tipo de ejercicios residía, para Romero Brest, en que se realizaban de forma individual, desalentando la acción conjunta. $^{41}$ También criticó la preparación física alemana por su carácter militar y la utilización de la fuerza. ${ }^{42}$ Las propuestas de la escuela inglesa, fundamentada en la utilización

\footnotetext{
${ }^{37}$ Enrique Romero Brest. Cursos Normales... pp. 54-55.

${ }^{38}$ En 1930, luego del golpe de Estado, se produjo un recambio de los elencos gubernamentales que tuvo repercusiones en el sistema educativo y generó varias cesantías y jubilaciones de oficio. Entre las personas que fueron obligadas a retirarse encontramos al Dr. Enrique Romero Brest. Pablo Scharagrodsky, "El padre de la... y Pablo Scharagrodsky. "La constitución de la...; Abel Agüero, Silvia Iglesias y Ana Del Valle Milanino. "Enrique Romero... Durante la década del '30 los profesores y figuras militares -egresadas de la Escuela de Gimnasia y Tiro del Ejército- volvieron a instalarse en la escena educativa; la reforma iniciada por el gobernador Manuel Fresco en la Provincia de Buenos Aires y la conformación del Consejo Nacional de Educación física demostraron esa nueva supremacía de la corporación castrense. El Consejo, creado mediante el decreto $\mathrm{N}^{\circ}$ 107.165 del 8 de junio de 1937 por iniciativa de la Dirección General de Tiro y Gimnasia del Ministerio de Guerra, tenía como propósito elevar al Poder Ejecutivo informes y proyectos sobre los métodos de educación física considerados pertinentes, proyectar lineamientos para una ley nacional de educación física y "la organización de un instituto nacional del profesorado”. Consultar Jorge Saraví Rivière. Historia de la ... p. 243.

39 Para un detalle de los ejercicios que se realizaban siguiendo los parámetros de la escuela francesa consultar Enrique Romero Brest. "Organización general de la enseñanza física”, El Monitor de la Educación Común, Año XXV, Tomo XX, No 389, (1905), pp. 851-877. También puede leerse una crítica a este método en Enrique Romero Brest. "Educación física. Como mejorarla en nuestras escuelas", El Monitor de la Educación Común, Año 35, Tomo 62, No 537, (1917), pp. 95-99.

40 Consultar en Enrique Romero Brest. Pedagogía de la Educación Física, (Buenos Aires: Cabaut y Cía. Editores, 1933), pp. 344-353.

${ }^{41}$ Enrique Romero Brest. "Organización general de...

${ }^{42}$ Pablo Scharagrodsky. "El Sistema Argentino de Educación Física. Entre el cientificismo, la higienización, el eclecticismo y la argentinidad", Revista Brasileira de Ciências do Esporte, 37(2), (2015), pp. 158-164, https://www.sciencedirect.com/science/article/pii/S0101328915000232?via\%3Dihub; Eduardo Galak. Del dicho al...
} 
de los deportes, podían tener consecuencias congestivas y además las competencias generaban esfuerzos dañinos para la salud. ${ }^{43}$

Tomó los aspectos que consideró positivos de la gimnasia sueca e incorporó algunos deportes con determinados recaudos; lo novedoso fue la invención de juegos, que luego devinieron en deportes como cesto ball o el pentathlos argentino. ${ }^{44}$ En palabras de su creador ideó “un sistema ecléctico que basado en la mecánica y fisiología del organismo respondiera al mismo tiempo a las exigencias de nuestros locales y de nuestro personal enseñante. ${ }^{45}$ Los métodos "exóticos" no podían satisfacer adecuadamente a la peculiaridad física y social de la población escolar argentina. La infraestructura y el material escolar también eran limitados, por ello el sistema propuesto no demandaba más que útiles para juegos y podía efectuarse en los patios que poseían las instituciones educativas. ${ }^{46}$ De esta manera, el sistema argentino nació a partir de una combinación, por un lado, de resistencia a aquellos lineamientos de las escuelas europeas con los que Romero Brest no acordaba y, por otro lado, de la apropiaciónadaptación de ideas y preceptos que estaban en boga en Europa. En definitiva fue el producto de la búsqueda, recepción e interpretación selectiva de saberes educativos que luego fueron adaptados a las particularidades del contexto nacional. ${ }^{47}$ En ese proceso de "nacionalización" y adaptación de conocimientos produjo nuevos saberes de Estado. ${ }^{48}$

¿En qué consistió, entonces, el sistema ideado por Romero Brest para la enseñanza de la educación física? Se sustentó en pilares como la fisiología, la higiene y la pedagogía. Sus propósitos fueron optimizar la salud, la energía muscular y por ende lograr una fortaleza

\footnotetext{
${ }^{43}$ El deporte fue un contenido excluido del currículum fundacional de la educación física; se cuestionó que no se realizaran desde un punto de vista fisiológico y pedagógico. Esta situación comenzó a cambiar hacia el año 1925, cuando aparece su referencia en los programas para la formación de profesores normales de educación física. Finalmente, esos contenidos serán incorporados a fines de la década de 1930, en un contexto de cuestionamiento del sistema "romerista" y con la modificación de los planes de estudio del Instituto Superior Nacional de Educación Física. Consultar Ángela Aisenstein. “Deporte y escuela ¿separados al nacer?”, Lecturas, Educación Física y Deporte, $\mathrm{N}^{\mathrm{o}}$ 11, Año 3, (1998), http://www.efdeportes.com/efd11a/angela.htm; Pablo Scharagrodsky. "Cartografiando acciones...; Diego Armus y Pablo Scharagrodsky. "El fútbol en las escuelas y colegios argentinos a principios del siglo XX. Enrique Romero Brest y el primer capítulo de una historia de (des)encuentros", XXVII Simpósio Nacional de História. Conhecimento histórico e diálogo social, Natal-Brasil, (2013),

http://www.snh2013.anpuh.org/resources/anais/27/1370306887_ARQUIVO_CONGRESO2013_NATAL_PON ENCIAJULIO.pdf y Alejo Levoratti. "El deporte en la...

${ }^{44}$ Pablo Scharagrodsky. El Sistema Argentino...

${ }^{45}$ Enrique Romero Brest. Cursos Normales... p. 57

${ }^{46}$ Enrique Romero Brest. La educación física...

47 Thomas F. Glick y Mark Henderson. "Las recepciones científicas y populares de Darwin, Freud y Einstein: hacia una historia analítica de la difusión de las ideas científicas", en El darwinismo en España e Iberoamérica, editado por Glick, Thomas F, Ruiz, Rosaura y Puig-Samper, Miguel A. (Madrid, UNAM-CSIC-Doce Calles, 1999), pp. 289-297. Antonio Nóvoa, Luis Miguel Carvalho, Antonio Carlos Correia, Ana Isabel Madeira y Jorge Ramos do Ó. "Los flujos del saber educativo. El espacio-tiempo en los países de lengua portuguesa", en Internacionalización. Políticas educativas y reflexión pedagógica en un medio global, compilado por Caruso, Marcelo y Tenorth, Heinz-Elmar, (Buenos Aires: Granica, 2011), pp. 345-392.

${ }^{48}$ Mariano Plotkin y Federico Neiburg. Intelectuales y expertos... p. 9.
} 
corporal; prestó especial atención a la respiración, el funcionamiento de los pulmones y el torax, dos aspectos centrales de la capacidad vital. También, entre los resultados esperados al realizar actividad física, destacó las derivaciones psíquicas y sociales. Por ello la propuesta racional y científica de Romero Brest preconizó una armonía entre la acción fisiológica y psicológica. $^{49}$

Su puesta en práctica se organizó en función de ejercicios metodizados de gimnasia fisiológica -vinculada a las mediciones corporales y el control científico-, los juegos, los deportes racionales y las rondas. ${ }^{50}$ Para que un ejercicio se considerara gimnástico debía delimitarse su objeto, velocidad, extensión, energía y dirección; comprendía tres momentos: posición inicial, ejecución del ejercicio y posición final. ${ }^{51}$ Un componente importante fueron los juegos educativos, que poseían una reglamentación específica. Estos se consideraban complementos de la gimnasia y estimulantes de la emoción; involucraban dos acciones: la fisiológica y la educativa. Con su práctica se ponían de relieve la habilidad, la precisión, la destreza física, pero también la capacidad de observación, de juicio respecto de las acciones y la serenidad para tomar decisiones en el juego. ${ }^{52}$ Además, permitía la incorporación de algunos deportes, entre ellos pelota al cesto -creado por el mismo Romero Brest-. ${ }^{53}$ Finalmente, otro elemento que caracterizó el método ideado por el galeno fueron las rondas escolares; todas referían a labores u oficios y los movimientos efectuados imitaban acciones realizadas por labradores, bomberos, entre otros. ${ }^{54}$

\footnotetext{
${ }^{49}$ Enrique Romero Brest. Evolución y consecuencias de las ideas doctrinarias en la educación física, (Buenos Aires: La Semana médica, 1911) y Pablo Scharagrodsky. "El Sistema Argentino...

${ }^{50}$ Para mayor información sobre los fundamentos del sistema argentino de educación física consultar Enrique Romero Brest. El Instituto Nacional Superior de Educación Física. Antecedentes, organización y resultados. (Buenos Aires: Cabaut y Cía., 1917), pp. 22-49; también Enrique Romero Brest. Bases de la Educación..., pp. 139-301.

${ }^{51}$ Todas esas etapas estaban claramente identificadas. Una clase completa de cultura física debía contener siete formas particulares de ejercicios en el siguiente orden: preliminares -los que incluían distintas posiciones-, torácicos, de equilibrio, de tronco, calmantes, sofocantes y respiratorios. Enrique Romero Brest. Pedagogía de la..., pp. 176-181.

${ }^{52}$ Estaban divididos, de manera práctica, según el efecto fisiológico que provocaban en preliminares, juegos de movimientos torácicos, juegos de equilibrio de ejercitación del tronco, de sofocación -salto, carrera, mixtos y lucha-. Enrique Romero Brest. Elementos de Gimnástica Fisiológica, (Buenos Aires: Librería del Colegio, 1939), pp. 106-284.

${ }^{53}$ Para Romero Brest ese deporte era mucho más apto para ser enseñado en las escuelas que el básquetbol o el fútbol, que terminaron siendo definitivamente masculinos, al menos en gran parte del siglo XX. "Este juego es uno de los más completos e importantes de los metodizados por el Instituto para el sistema argentino; se usa para complementar los efectos analíticos de la gimnasia con los sintéticos de los juegos y deportes (...). Forma parte del péntatlo argentino integrado por la pelota cazadora, la pelota al blanco, el salto de precisión y la carrera de banderitas (...). Desde el punto de vista psíquico y social determina las situaciones de todo el juego deportivo racional. Obliga a la solidaridad, la energía en la acción, las determinaciones rápidas y decisivas para la ejecución de una buena táctica en la lucha. Finalmente es altamente atractivo para ambos sexos y para todas las edades de doce a dieciocho años”; ver Enrique Romero Brest. Elementos de Gimnástica, pp. 411-412 y 418-419. ${ }^{54}$ Entre ellas podemos mencionar las del lobo, del trigo -que incluía diferentes momentos como marchar al trigal, labrar la tierra, sembrar el trigo, segarlo, engavillarlo, cargar el trigo en los carros, transportarlo,
} 
Era simple, según su ideólogo, llevar a la práctica este sistema de enseñanza; bastaba con un patio amplio, aire libre y no eran necesarios los aparatos. Su difusión se realizó desde el Instituto Superior de Educación Física; en sus aulas se formaron los futuros profesores encargados de esa asignatura escolar. Los lineamientos del sistema argentino definieron también los contenidos a enseñar en las instituciones educativas. La propuesta de Romero Brest no fue producto de la improvisación, sino el fruto de arduos estudios que pueden definirse como parte de la dimensión transnacional del doble proceso de construcción de saberes sociales y de Estado. ${ }^{55}$ En este sentido, formó parte de la producción científica de su época; sus hipótesis y postulados fueron "considerados racionales, objetivos, mensurables y, sobre todo, incuestionables". 56 La matriz positivista decimonónica suministró los conocimientos científicos que luego se convirtieron en reglas de acción para ser aplicadas por los docentes y practicadas por los estudiantes.

\section{Fundamentar científicamente la educación física: el laboratorio de Fisiología y Antropometría}

Una condición primordial, para aplicar con éxito un sistema de educación física en el ámbito escolar, era su metodización científica basada en "observaciones minuciosas, antropométricas y fisiológicas." $" 57$ En el Instituto de Educación Física, en paralelo a la formación de profesionales, se realizaron investigaciones científico-experimentales sobre los procedimientos que permitieran lograr una cultura física higiénica. ${ }^{58} \mathrm{La}$ aplicación racional de la cultura física se sustentó en la fisiología; ningún organismo humano escapaba a sus leyes. Una norma básica era que "la función hace al órgano y determina sus variaciones". 59 Para un completo perfeccionamiento había que llegar al mayor grado de actividad funcional de ese órgano. Así, la educación física adquiría un rol central; sin embargo, era necesario conocer los efectos que los ejercicios provocaban para lograr el beneficio corporal deseado. Esos saberes

descargarlo, trillarlo, molerlo y culminaba con el baile de los labradores-, de la avena, de los bomberos, de los juegos, del marinero, del carpintero, del curtidor. Estas rondas estaban acompañadas del canto y la música. Pueden consultarse la letra y música de las rondas escolares en Enrique Romero Brest. Elementos de Gimnástica..., pp. 506-577.

${ }^{55}$ Mariano Plotkin y Eduardo Zimmermann. Los saberes del Estado, (Buenos Aires: Edhasa, 2012).

${ }^{56}$ Pablo Scharagrodsky. El Sistema Argentino..., p. 160

${ }^{57}$ Enrique Romero Brest. Curso Superior de Educación Física. Bases científicas y aplicaciones prácticas. Tomo II: Pedagogía y Práctica de la Educación Física, (Buenos Aires: Librería y Casa Editora de Nicolás Marana, 1903), p. 186.

${ }^{58}$ Sobre este tópico consultar Enrique Romero Brest. "Orientación científica de la cultura física", El Monitor de la Educación Común, Año XXVIII, Tomo XXVIII, No 434, (1909), pp. 290-303; Eduardo Galak. Del dicho al...

${ }^{59}$ Enrique Romero Brest. Pedagogía de la ..., p. 6. 
permitirían luego deducir "las reglas metodológicas e higiénicas fundamentales" para su aplicación en la escuela; este tema había sido una preocupación central en la tesis de Romero Brest. $^{60}$

También los futuros egresados del Instituto adquirían conocimientos sobre anatomía humana aplicada a la educación física y los complementaban con estudios sobre el movimiento. ${ }^{61}$ En el ámbito del laboratorio se dictaban las clases prácticas de fisiología experimental, apoyadas en las lecciones teóricas. Los tópicos que abordaban en fisiología eran la variación del pulso radial, a partir de esfigmograma, y la comparación de esos resultados con los del pulso en reposo o durante ejercicios sofocantes, de tronco y respiratorios. La potencia muscular podía calcularse por medio de la fuerza aislada o de la resistencia física. Algunos de los aparatos utilizados para esas evaluaciones fueron los dinamómetros y dinamógrafos. También se indagó sobre la fatiga de los músculos, utilizando el ergógrafo de Mosso. $^{62}$ Otro tema de considerable importancia era el estudio de la variación de los volúmenes pulmonares en diferentes actividades, a partir del espirómetro de Tissot. Estas pruebas de la función pulmonar, o espirometría, permitían evaluar el grado de disfunción del aparato respiratorio. ${ }^{63}$ Las mediciones se realizaban calculando la cantidad de aire contenida en los pulmones y tomando las medidas torácicas, como el diámetro y la circunferencia, utilizando el citómetro o toracómetro. Para efectuar este último control Romero Brest inventó una cinta metálica o cartómetro. ${ }^{64}$

Como anexo al laboratorio de fisiología organizó una sección de antropometría. Allí se medían las dimensiones y longitudes corporales y se recolectaban datos relacionados con las pruebas de saltos en largo, en alto, carreras de velocidad, entre otras. ${ }^{65}$ Desde la cátedra de

\footnotetext{
${ }^{60}$ Enrique Romero Brest. El Instituto Nacional..., p. 75.

${ }^{61}$ Enrique Romero Brest. El Instituto Nacional..., pp. 72-74.

${ }^{62}$ A fines del siglo XIX en Europa surgieron una serie de preocupaciones relacionadas con la productividad de los cuerpos. Así, nuevos saberes "midieron y vincularon la productividad y la fatiga"; entre sus principales referentes destacamos a Ángelo Mosso y Philippe Tissié. La atención se puso en el peso, la estatura, la circunferencia torácica de la población y la educación física se impuso como la solución para regenerar los cuerpos. Estas ideas arribaron a Argentina y fueron recogidas por autores como Bialet Masse, Augusto Bunge y Alfredo Palacios; consultar Diego Roldán. "Discursos alrededor del cuerpo, la máquina, la energía y la fatiga: hibridaciones culturales en la Argentina fin-de-siecle”, História, Ciências, Saúde, Vol.17, №3, (2010), pp.643661. Para realizar esas mediciones Ángelo Mosso creó el ergógrafo. Instrumento que permitía estudiar la aparición y posterior evolución del estado de fatiga muscular.

${ }^{63}$ Varios estudiosos idearon aparatos para medir la capacidad pulmonar como el pulmómetro de Edward Kentish o el espirómetro de John Hutchinson; este fue el primero en plantear la idea de la capacidad vital espiratoria.

${ }^{64}$ Juan Renda. Brest, un investigador pionero, (Buenos Aires: Ministerio de Educación, Dirección General de Educación Superior, 2007).

${ }^{65}$ Estas mediciones permitían elaborar bases de datos, contar con conocimientos sobre el desarrollo corporal, entre otros. Pablo Scharagrodsky. "Dime como te mueves y te diré cuál es tu "sexo": discurso médico, educación física y diferencia sexual a finales del siglo XIX y principios del siglo XX", en Moralidades y comportamientos sexuales. Argentina, 1880-2011, editado por Barrancos, Dora; Guy, Donna y Valobra, Adriana, (Buenos Aires: Biblos, 2014), pp. 73-94.
} 
Biometría, materia incluida al plan de estudio de la formación docente en educación física desde 1925, se sentaron las bases teóricas que luego permitirían elaborar los cálculos y cuantificaciones pertinentes. ${ }^{66}$ Así, se verificaban la edad, la talla, utilizando el tallímetro milimétrico en posición de pie y sin calzado, y la masa corporal empleando una balanza. Dentro de los controles antropométricos se medía el perímetro del tórax (con una cinta métrica a la altura de las axilas) que resultaba del valor referente a la diferencia entre la medición del pecho en proceso de inspiración y en espiración. Además, se registraba el diámetro torácico por medio del torocógrafo. ${ }^{67}$

La antropometría fue uno de los saberes biomédicos que estuvo presente en el campo pedagógico y las mediciones-clasificaciones corporales dieron cuenta de las preocupaciones por la salud, el crecimiento físico y las variables que demostraran el "normal" desarrollo de los educandos, identificando como contrapartida a los no aptos o anormales. La ciencia nacida del positivismo comtiano "se convertiría en una de las herramientas fundamentales para la normalización social, para la restitución a la "norma" moral de los "desviados". ${ }^{68} \mathrm{El}$ interés por controlar el desarrollo y la evolución de los niños y jóvenes estaba vinculado a la prevención de enfermedades y detección de posibles debilidades. El diagnóstico cumplía un papel fundamental para identificar esos casos y luego aplicar los remedios pertinentes. Muchas veces se recomendaban la práctica de ejercicios metodizados y juegos al aire libre, ya que producían efectos higiénicos, estéticos, económicos y morales. ${ }^{69}$ Para Romero Brest no sólo eran imperiosos los ejercicios que robustecieran los cuerpos, también era preciso que la

\footnotetext{
${ }^{66} \mathrm{La}$ biometría fue definida "como un corpus de conocimientos cuyo fin era el estudio cuantitativo de los fenómenos vitales. Una de sus finalidades fue determinar las leyes que regían los fenómenos biológicos, siendo la estadística la matriz central hermenéutica para explicar y predecir todas las ciencias humanas incluyendo a la pedagogía, la educación, a los deportes y a la Educación Física"; consultar Pablo Scharagrodsky. "Los arquitectos corporales en la Educación Física y los Deportes. Entre fichas, saberes y oficios (Argentina primera mitad del siglo XX)", Trabajos y Comunicaciones, 2da Época, $\mathrm{N}^{\mathrm{o}} 42$, (2015), p. 4, http://www.trabajosycomunicaciones.fahce.unlp.edu.ar/article/view/TyC2015n41a05.

${ }^{67}$ Enrique Romero Brest. Pedagogía de la..., p. 268-296.

${ }^{68}$ Rafael Huerta. "Medicina social, control social y políticas del cuerpo. La subjetivación de la norma", en Cuerpo, biopolítica y control social. América Latina y Europa en los siglos XIX y XX, coordinado por Marisa Miranda y Álvaro Girón Sierra, (Buenos Aires: Siglo XXI, 2009), p. 21. Consultar también María Silvia Di Liscia. "Los bordes y límites de la eugenesia donde caen las 'razas superiores' (Argentina, primera mitad siglo XX)", en Políticas del cuerpo. Estrategias modernas de normalización del individuo y la sociedad, editado por Vallejo, Gustavo y Miranda, Marisa (Buenos Aires: Siglo XXI, 2008), pp. 377-409; Abel Agüero, Ana del Valle Milanino, Elías Bortz y Marcos Isolabella. "Precursores de la Antropometría Escolar en la Ciudad de Buenos Aires: Luis Cassinelli, Genaro Sisto, Juan P. Garrahan, Saúl Bettinotti y Cornejo Sosa”, eä Journal, Vol. 4 N 1 , (2012), http://www.ea-journal.com/images/stories/Arts0401/Articulo_-_Aguero_et_al-Precursores.pdf; Pablo Scharagrodsky. Los arquitectos corporales...

${ }^{69}$ Consultar Enrique Romero Brest. "Desarrollo de una clase de ejercicios físicos", El Monitor de la Educación Común, Año XXV, Tomo XX, No 384, (1905), p. 649.
} 
actividad física se realizara "en lugares y medios apropiados". El aire puro desempeñaba así un papel tan importante como el ejercicio mismo para concretar el perfeccionamiento físico. ${ }^{70}$

Ese entusiasmo por la medición, la experimentación, la predicción el registro y el control de los cuerpos se enmarca en los postulados científicos de su época, que aplicaron los métodos, conceptos y objetivos de las ciencias naturales al análisis de las sociedades. ${ }^{71}$ En este sentido, apelaron a leyes y metodologías de las ciencias con carácter de neutralidad e imparcialidad. Esas ideas impregnaron el pensamiento de Romero Brest que trató incansablemente de otorgar una fundamentación rigurosa a la educación física, la que no podía prescindir de los conocimientos médicos y fisiológicos. ${ }^{72}$ Los trabajos de laboratorio e investigaciones sobre fisiología originaron discursos científicos sobre el cuerpo y las manifestaciones visuales se utilizaron a modo de prueba de esos procesos de experimentación y construcción de saberes. Así, en el Instituto de Educación física funcionó también un laboratorio de fotografía; las imágenes tomadas "encubiertas en un ideal de objetividad inmediata (mecánica), construían y reproducían convenciones sobre la naturaleza, la corporalidad y la identidad."73

Los saberes producidos en el laboratorio debían divulgarse; así nació la Revista de Educación Física. En sus páginas se expusieron aspectos vinculados al conocimiento legítimo sobre la asignatura y su valor social, se presentaron teorías e hipótesis sobre "el cuerpo humano individual (su organización y funcionamiento) y sobre el cuerpo social (su reproducción y gobierno)." ${ }^{74}$ Desde esa publicación se llevó a cabo por un lado, la construcción disciplinar de la educación física como ciencia y, por el otro, su configuración

\footnotetext{
${ }^{70}$ Enrique Romero Brest. Pedagogía de la ..., p. 297.

71 "Los anatomistas del siglo XIX popularizaron las medidas de los cuerpos, que Lamarck o Darwin les enseñaron a derivar según las especies, las razas, el tiempo", Georges Vigarello. Historia de la belleza: El cuerpo y el arte de embellecer desde el renacimiento hasta nuestros días (Buenos Aires: Nueva Visión, 2005), p. 173. Sin embargo, no podemos dejar de mencionar que de ese modo se justificó la primacía de la sociedad blanca y occidental.

72 "Es indudable el influjo que la físiología alemana tuvo para el desarrollo de las ciencias médicas del siglo XIX. Partiendo de la premisa enunciada por Helmholtz acerca de que la medicina será una ciencia natural o no será nada, los positivistas germanos desarrollaron una ciencia fisiológica antivitalista, física, analítico-causal, cuantitativa, instrumental y experimental", Abel Agüero, Silvia Iglesias y Ana Del Valle Milanino. "Enrique Romero..., p. 21. Para esta concepción la observación, la medición y el registro de los fenómenos era fundamental. Estos postulados cientificistas favorecieron la invención de aparatología médica.

${ }^{73}$ Andrea Torricella. "Cultura física, discurso científico y usos de la fotografía. Convergencias epistemológicas en torno a las re-presentaciones del cuerpo, Argentina 1910-1940", en Miradas médicas sobre la cultura física en Argentina. 1880-1970, (Buenos Aires: Prometeo, 2014), p. 15. La fotografía tuvo una importancia considerable en el desarrollo de la psiquiatría, la criminología y la antropología; también se utilizó en los estudios de las ciencias biológicas sobre el cuerpo y sus movimientos. En este sentido, Etienne-Jules Marey tomaba fotografías, presentando en una misma hoja de película varias exposiciones y de esta manera registró las distintas posiciones del cuerpo humano. La crono-fotografía también fue un tema presente en el Congreso de Educación Física de 1913; consultar Pablo Scharagrodsky y Jacques Gleyse. "El Dr. Enrique...

${ }^{74}$ Ángela Aisenstein, Cuerpo, escuela y..., p. 74. Consultar también Eduardo Galak. Del dicho al...
} 
como asignatura escolar. Esos saberes fueron construidos en la intersección de dos campos disciplinares como el de los fisiólogos e higienistas y el de los pedagogos. ${ }^{75}$ De esta manera, los discursos médicos impregnaron la formación de los profesores en el Instituto, las investigaciones efectuadas y ello quedó plasmado en la posterior difusión. ${ }^{76}$

\section{El control del cuerpo individual (y social) en la mira de Romero Brest}

La producción de conocimientos por intelectuales y expertos, vinculados a determinados campos disciplinares, se entrelazó con las demandas del Estado y con la conformación de las elites encargadas de producir, transmitir y aplicar estos conocimientos. Tanto en las gestiones de los gobiernos conservadores (1880-1916), como durante los gobiernos radicales (1916-1930), desde diversas agencias estatales se buscó responder y actuar en relación a la denominada cuestión social. El higienismo, la medicina social, la criminología, entre otras disciplinas, desarrollaron conocimientos y propusieron reformas para resolver problemáticas como las sanitarias, la cuestión obrera, la delincuencia, las condiciones de vida, la vivienda, entre otras. ${ }^{77}$ En este contexto se enmarca la producción de saberes forjados por Enrique Romero Brest. Sus razonamientos científicos y pedagógicos buscaron dar respuesta a ciertas problemáticas sociales como la construcción de la nacionalidad, el mantenimiento del orden, la reproducción y formación de los futuros trabajadores.

El objetivo primordial del trabajo físico escolar fue la conservación de la salud y el desarrollo armónico del cuerpo; su adiestramiento era el dispositivo más adecuado para la higiene, la conservación de las energías y el acrecentamiento de la resistencia. Los músculos que se trabajaban y ejercitaban tenían un desarrollo superior, se fortificaban y por lo tanto presentaban mayor potencialidad. ${ }^{78}$ De esa manera, los ejercicios mejoraban la circulación, la respiración, el metabolismo y evitaban las enfermedades, contribuyendo a forjar cuerpos sanos y robustos. ${ }^{79}$ Contribuir al perfeccionamiento y la salud corporal de los individuos tenía

\footnotetext{
${ }^{75}$ Enrique Romero Brest. "Concepto moderno de la Educación física”, El Monitor de la Educación Común, Año XXV, Tomo XX, No 385, (1905), p. 401.

${ }^{76}$ Tanto los cursos temporarios como el curso Normal de Educación física presentaron contenidos provenientes del discurso médico. En este último caso se anexaron materias específicas como Anatomía humana aplicada a la educación física y Fisiología del ejercicio, que incorporaron bloques temáticos específicos sobre el cuerpo humano. Consultar Pablo Scharagrodsky. El discurso médico...

${ }^{77}$ Eduardo Zimmermann. Los liberales reformistas. La cuestión social en Argentina 1890-1916 (Buenos Aires: Sudamericana, 1995); Juan Suriano. La cuestión social en Argentina: 1870-1943 (Buenos Aires: La Colmena/Grupo de Trabajo Movimiento Obrero y Sectores Populares, 2000).

${ }^{78}$ Romero Brest, Enrique. Evolución y consecuencias...

${ }^{79}$ Enrique Romero Brest. La orientación social de la educación física, (Buenos Aires: Talleres gráficos de la Penitenciaría Nacional, 1909).
} 
como correlato un valor para la sociedad. En palabras del galeno "la energía social es la suma de las energías individuales, y en consecuencia, el aumento o la disminución de estas contribuye a modificar aquellas. Los sujetos débiles son, en este sentido, antisociales y conspiran contra la existencia y el progreso de las sociedades a que pertenecen." 80

Así, Romero Brest planteaba que cultivar la fuerza muscular de manera aislada no generaba valor social. La educación física tenía una finalidad utilitaria al incrementar la energía, la salud y la fuerza muscular. Los trabajadores del campo, los obreros de los talleres, el futuro soldado y hasta los estudiosos necesitaban modos especiales de solucionar físicamente las cuestiones que cotidianamente se les presentaban, adquirir habilidades manuales y destrezas según sea el caso. El hombre sano producía más que el enfermo o el débil "porque la euforia física y la alegría de vivir que generalmente le acompaña dirigen su acción y sentimientos provocando la mejor y más eficaz aplicación de sus energías.” Antagónicamente, el hombre enfermo era un problema para la comunidad puesto que provocaba "gastos y rémoras sociales por el cuidado que suscita" y exigía "hospitales, casas de caridad, asociaciones de beneficencia, etc."

Numerosos representantes del discurso médico, políticos y educadores defendieron la idea de que en un tórax atlético e "inteligentemente trabajado" no entraría la tuberculosis. En este sentido, el fortalecimiento de los cuerpos era una garantía para la salud. La gimnasia respiratoria y la ejercitación corporal fueron recurrentes a la hora de evitar la tuberculosis en hombres y mujeres, pero sobre todo en los niños. Los saberes médicos identificaron varias causas entre los orígenes de esa enfermedad: los nacimientos prematuros, vivir en ambientes húmedos y poco aseados, el raquitismo, la anemia, entre muchas otras. Así, los esfuerzos se concentraron en mejorar las condiciones de quienes eran propensos a enfermarse, es decir el colectivo denominado "niños débiles". 82

También Romero Brest refirió al trasfondo moral de las prácticas físicas, así trascendían el ámbito puramente orgánico y se trasladaban a lo social. Las actividades

\footnotetext{
${ }^{80}$ Enrique Romero Brest. Pedagogía de la..., p. 49.

${ }^{81}$ Enrique Romero Brest. Bases de la Educación..., pp. 169-170.

${ }^{82}$ Diego Armus. La ciudad impura. Salud, tuberculosis y cultura en Buenos Aires, 1870-1950, (Buenos Aires: Edhasa, 2007). El cuidado sanitario de la infancia fue una prioridad y para ello se creó un entramado de agencias estatales con la finalidad de cuidar y preservar médicamente a los niños. El sistema educativo no permaneció ajeno y desde su conformación al interior de las escuelas se prestó atención a la higiene y salud de los escolares e incorporaron conocimientos y prácticas provenientes del campo de la medicina. María Silvia Di Liscia. "Médicos y maestros. Higiene, eugenesia y educación en Argentina (1880-1940)", en Higienismo, Educación y discurso en la Argentina (1870-1940), editado por Di Liscia, María Silvia y Salto, Graciela, (Santa Rosa: EdUNLPam, 2004), pp. 37-64; Lucía Lionetti. "Discursos, representaciones y políticas educativas en torno a los 'niños débiles' en Argentina a comienzos del siglo XX”, en Espacios en Blanco. Revista de Educación, vol. 18 (2008), pp. 187-213, http://espaciosenblanco.unicen.edu.ar/pdf/numerorosanterior/Revista_Espacios_en_Blanco_N18.pdf.
} 
gimnásticas se convertían entonces en preventivas de las influencias perniciosas de la civilización como el ocio, o de "lacras sociales" como el alcoholismo, el tabaquismo y la prostitución. En los espacios urbanos la población se veía afectada por hábitos de la vida moderna, que tenían como contracara el nerviosismo, la inactividad y el sedentarismo (provocados por los nuevos medios de locomoción); estos males desencadenaban algunas afecciones como "la gota" o "la obesidad." La gimnasia y los campos de ejercicio físico poseían así un valor trascendental ya que arrancaban al "niño de las calles, de los cafés, de las casas de juego y de los espectáculos malsanos, para llevarlo al aire libre a tomar el mejor remedio contra sus debilidades psíquicas." $" 83$

Estas ideas se reiteraron a lo largo de sus escritos. Sostenía que la instalación de plazas de juegos favorecía la clausura de los hospitales, el cierre de las tabernas y el despoblamiento de las cárceles. ${ }^{84}$ Inspirado en las concepciones eugenésicas de la época presuponía que el sedentarismo y la falta de actividad muscular conducían a la degeneración de la raza. ${ }^{85}$ En la búsqueda de mejorar la aptitud psicofísica de la población una de las estrategias propuesta como correctiva fue la educación física. De la mano de cátedras como Biometría ingresaron al Instituto Superior de Educación Física los discursos eugenésicos más “coercitivos" y normalizadores. ${ }^{86}$

La política somática del sistema argentino de educación física impactó en forma diferencial sobre los cuerpos al forjar cierta feminidad y masculinidad. Los profesionales médicos intervinieron en la construcción cultural de la dicotomía sexual e identificaron las anatomías "adecuadas" y aquellas que consideraron como "anormales". ${ }^{87}$ La diferencia corporal fue construida entonces a partir del discurso médico, ${ }^{88}$ preocupado por la salud de la

\footnotetext{
${ }^{83}$ Enrique Romero Brest. Pedagogía de la..., pp. 18-19.

${ }^{84}$ Romero Brest, Enrique. Curso Superior de..., pp. 163. Desde fines del siglo XIX problemáticas como el hacinamiento de la población, el alcoholismo, la prostitución, las enfermedades mentales, la desnatalidad y el deterioro físico de la población movilizaron a intelectuales y burócratas. De esa manera se fueron delineando las concepciones eugenésicas que arraigaron en higienistas, puericultores y promotores de la cultura física. Andrés Reggiani. "Eugenesia y cultura física. Tres trayectorias históricas: Francia, Gran Bretaña y Argentina", en Miradas médicas sobre la cultura física en Argentina. 1880-1970, compilado por Scharagrodsky, Pablo, (Buenos Aires: Prometeo, 2014), pp. 17-58; Marisa Miranda. "La Argentina en el escenario eugenésico internacional", en Una historia de la Eugenesia. Argentina y las redes biopolíticas internacionales 1912-1945, dirigido por Miranda, Marisa y Vallejo, Gustavo, (Buenos Aires: Editorial Biblos, 2012), pp.19-64.

${ }^{85}$ Galak, Eduardo. Educación del cuerpo...; Silvina C. Franceschini. Discursos y prácticas de la eugenesia en la formación de profesores en Educación física en Argentina durante la entreguerra. Los casos del INSEF de Buenos Aires y San Fernando (Tesis de maestría), (Buenos Aires: Universidad Nacional de Quilmes, 2020), http://ridaa.unq.edu.ar/handle/20.500.11807/2950.

${ }^{86}$ Scharagrodsky, Pablo. El discurso médico...

${ }^{87}$ Scharagrodsky, Pablo. Dime como te mueves...

${ }^{88}$ Desde fines del siglo XIX los médicos describieron el cuerpo femenino y lo hicieron comparándolo con el de los varones. Así, se las presentó como "menos sólidas, menos macizas, más livianas, menor curvatura, menor altura total, inferior", entre otras características. Anatómicamente también se las consideró más frágiles en sus huesos, músculos, articulaciones. Consultar Pablo Scharagrodsky. Dime como te mueves..., p. 78 y Diego
} 
futura madre y apoyado en la creencia de que sólo las mujeres robustas podrían tener una descendencia fuerte. "La robustez y debilidad física de la mujer no solo afecta al individuo aislado sino también y muy directamente a la raza. Es pues así una cuestión social de alta trascendencia la que se afecta con el problema de la educación física de la mujer: el perfeccionamiento de la raza." $" 89$

Para Romero Brest la educación física en las futuras madres era esencial, ya que cuidar de ellas era asegurar la "potencialidad de los hijos". Las diferencias fisiológicas entre el hombre y la mujer se centraban en el desarrollo de la "pelvis y especialmente de los órganos de esencia femenina, como la matriz." Identificó ejercicios que podían ser perniciosos para esos órganos delicados; ellos eran los saltos y las carreras, y en general los deportes y las actividades atléticas de extrema violencia. Asimismo, alegó sobre la necesidad de evitar adiestramientos que lesionaran el decoro femenino y masculinizaran a la mujer; inclusive, el uniforme que debían utilizar las niñas y jóvenes era también objeto de especial cuidado "para conservar la femineidad." 90 Recomendaba los ejercicios "de estética, de armonía de las formas, de la gracia de los movimientos, más que los de fuerza o violencia", considerados los más apropiados para la fisiología femenina. ${ }^{91}$ La gracia, la suavidad y la elegancia debían primar en la ejecución de sus prácticas gimnásticas, ya que las futuras madres exigían cuidados especiales de la pelvis y de la pared abdominal. ${ }^{92}$

Así, la feminidad fue asociada con ciertas características corporales y se recomendaron prácticas que beneficiaran su rol maternal, apostando a la procreación y el regeneramiento racial. Con respecto a los varones, también esa disciplina funcionó como dispositivo ortopédico, al adiestrar los comportamientos masculinos y corregir aquellos considerados indeseables o incorrectos. La paternidad no era el fin perseguido, sino la ejercitación de hombros y brazos favoreciendo las demandas del Estado que necesitaba músculos fuertes, es decir trabajadores sanos. ${ }^{93}$

La formación integral de hombres y mujeres estuvo estrechamente vinculada a su constitución como seres fuertes y sanos, con el objetivo de mejorar la especie, vigorizar la raza y producir riqueza para la nación. Ello implicaba intervenir sobre los cuerpos,

\footnotetext{
Armus. "La cultura física de las mujeres, la moda del corsé y los ignorados consejos de los médicos. Buenos Aires 1870-1940", en Mujeres en movimiento. Deporte, cultura física y feminidades. Argentina, 1870-1980, coordinado por Scharagrodsky, Pablo, (Buenos Aires: Prometeo, 2016), pp. 23-48.

${ }^{89}$ Enrique Romero Brest La educación física de la mujer, (Buenos Aires: Librería y casa Editora de Nicolás Marana, 1903).

${ }^{90}$ Enrique Romero Brest. Bases de la Educación ..., pp. 220-224.

${ }^{91}$ Enrique Romero Brest. Pedagogía de la ..., p. 88.

${ }^{92}$ Enrique Romero Brest. Pedagogía de la ..., p.148.

${ }^{93}$ Pablo Scharagrodsky, El padre de la...
} 
disciplinándolos y encauzándolos hacia las conveniencias de la sociedad. En ese sentido, las elites estatales apoyadas en el saber profesional que poseían buscaron producir y reproducir instrumentos para analizar esas problemáticas sociales y generaron estrategias biopolíticas de gestión. ${ }^{94}$ Desde el Estado, en tanto "estructura organizativa e instancia reguladora" se ejerció una acción formadora "a través de todas las coerciones y de las disciplinas corporales y mentales." Además, se impusieron e inculcaron "todos los principios de clasificación fundamentales, según el sexo, según la edad, según la competencia." 95

Así, el saber científico buscó fabricar cuerpos por medio de una estricta disciplina; Romero Brest la definía como la "tendencia y el hábito a la ejecución correcta y precisa de todos los movimientos", sustentada en "el comportamiento del alumno como individuo racional y libre, en la obediencia estricta a las órdenes del maestro.” Esas prácticas actuaron como técnicas de ejercicio de poder y permitieron vigilar y controlar los cuerpos, en definitiva regular la población. Estas intervenciones buscaron "tomar a cargo la salud y la vida de los individuos, es decir modificar el destino biológico de la especie humana." ${ }^{\text {"6 }}$ La disciplina también se caracterizó por registrar y hacer inteligible cada una de las estrategias de dominación corporal, codificando lo que estaba permitido y prohibido. ${ }^{97}$

\section{A modo de cierre}

Si bien los posicionamientos de Romero Brest, y los incondicionales que acompañaron sus opiniones, mantuvieron la hegemonía en el campo de la educación física por el trascurso de tres décadas, hacia los años veinte se produjeron los primeros cuestionamientos a su propuesta. Hacia 1922 comenzaron ciertas tensiones y enfrentamientos al interior de la Asociación de Profesores de Educación Física. Ese año, en el contexto de las elecciones para renovar las autoridades se presentaron dos listas, una de ellas patrocinada por el mismo Enrique Romero Brest. Sin embargo, resultó triunfante el grupo opositor y unos días después Romero Brest renunció a la Asociación argumentando que la misma se había alejado de los propósitos que motivaron su creación y sus intereses eran diferentes de las opiniones sustentadas por ese socio fundador. Los profesores del Instituto Nacional de educación física

\footnotetext{
${ }^{94}$ Michel Foucault. Nacimiento de la biopolítica, (Buenos Aries: Fondo de Cultura Económica, 2008).

${ }^{95}$ Pierre Bourdieu. "Espíritus de Estado. Génesis y estructura del campo burocrático", en Razones prácticas. Sobre la teoría de la acción de Pierre Bourdieu, (Barcelona: Anagrama, 1997), p. 117.

${ }_{96}$ Michel Foucault. Historia de la sexualidad. La voluntad del saber, (Buenos Aires: Siglo XXI, 2008), p. 27.

${ }^{97}$ Michel Foucault. Seguridad, territorio y población, (Buenos Aires: Fondo de Cultura Económica, 2007).
} 
también se distanciaron de la Asociación. A partir de ese momento comenzaron una serie de acusaciones cruzadas entre ambos grupos. ${ }^{98}$

En esa puja de intereses su autoridad fue cuestionada y comenzó a perder legitimidad. ${ }^{99}$ Además de la ruptura con la Asociación, la creación de la Comisión Técnica de Educación Física (1924) vislumbró la necesidad de revisar el sistema y los métodos para su enseñanza y difusión. Algunos de sus integrantes mantenían puntos de vista disímiles de los del "padre" de la educación física, como Arsenio Thamier, director de la Escuela de Tiro y Gimnasia del Ejército, u Horacio Levene. ${ }^{100}$ En ese contexto surgieron críticas a la formación que se impartía desde el Instituto, a la escasa relevancia que poseía en materia deportiva y la poca inserción que tenían sus egresados. En contraposición la Asociación publicó en la revista La Obra argumentos planteando que "el número de catedráticos sin título que enseñan la disciplina demuestra una despreocupación oficial por el porvenir y el aprovechamiento de los profesionales que el Estado costea y gradúa. ${ }^{101}$

Quedó claramente explicitada la presencia de los militares en esos intentos por definir los contenidos y la formación de los docentes de la asignatura. Figuras como Levene o el General Adolfo Arana tuvieron un protagonismo central en ese proceso de cambios. Ambos defendieron una propuesta de cultura física militarizada y rompieron con los postulados de Romero Brest en un contexto signado por el nacionalismo, los valores castrenses y católicos. ${ }^{102}$ Finalmente, y luego de una hegemonía de aproximadamente treinta años, el sistema argentino de educación física fue derogado en 1939. En los considerandos de la resolución ministerial aparecen menciones como "evitar la aplicación de métodos o sistemas que no responden a las necesidades de la enseñanza.",103

No caben dudas de que Romero Brest fue un referente indiscutible en el plano epistémico y del saber, ya que generó conocimientos relacionados con una educación física científica. A lo largo de estas páginas reconstruimos su itinerario formativo y el recorrido profesional, trayectoria que comenzó en el Instituto Nacional de Caballito. Ese fue su punto de partida en el campo de la educación física escolar; luego vendrían otros mojones en su carrera, como la tesis que le permitió graduarse de médico. A partir de allí se incorporó como

\footnotetext{
${ }^{98}$ Scharagrodsky, Pablo. "Cartografiando acciones...; Scharagrodsky, Pablo. "El discurso médico...

${ }^{99}$ Pierre Bourdieu. Campo de poder, campo intelectual. Itinerario de un concepto (Buenos Aires: Editorial Montressor, 2002).

${ }^{100}$ Pablo Scharagrodsky. "La constitución...

${ }^{101}$ Galak, Eduardo. Del dicho al hecho... p. 142

102 Pablo Scharagrodsky. "La constitución...

${ }^{103}$ Consultar la Resolución No 19 del Ministro de Justicia e Instrucción Pública, 6 de marzo de 1939, "Fijando las normas para la enseñanza de la educación física en las Escuelas Normales de la República", en Boletín del Ministerio de Justicia e Instrucción Pública, Año 2, No 6, $1^{\circ}$ de enero al 22 de marzo de 1939, pp. 205-206.
} 
técnico al servicio del Estado; participó y tuvo injerencia en la definición de los contenidos curriculares para la educación física escolar y desde la instauración de los cursos temporarios, luego en la Escuela Normal de Educación Física y finalmente en el Instituto, ejerció un rol central en la formación de los futuros docentes de la asignatura. A su vez, al desempeñarse como Inspector advirtió las problemáticas que aquejaban a la enseñanza de la gimnasia y propuso trasformaciones en los contenidos y la formación de profesores y maestros. De esa forma, fue artífice en los lineamientos y orientaciones de la política educativa estatal al elaborar planes y programas de estudio e instruir a los profesionales encargados de dictar esa asignatura.

Fue posicionándose públicamente y adquirió en el ejercicio de su profesión prestigio y autoridad científica, convirtiéndose en un especialista en la materia. Sus estudios y reflexiones lo llevaron a crear un método de instrucción adecuado a las particularidades de las escuelas de su país. Así surgió el sistema argentino de educación física; fue una adaptación e hibridación de saberes, pero también incorporó innovaciones como por ejemplo pelota al cesto. De esta manera, generó saberes de Estado; estos se producen en la intersección de, por un lado, el entrecruzamiento de campos disciplinares en construcción con las demandas del Estado y, por otro lado, la conformación de las elites encargadas de producir, transmitir y aplicar estos conocimientos. Las investigaciones que llevó a cabo y las propuestas que efectuó contribuyeron a la producción de conocimiento social, que se apoyó en el diagnóstico de determinadas problemáticas y la solución de las mismas mediante políticas concretas. ${ }^{104}$

Las prácticas científicas en tanto prácticas sociales, se enmarcan en un contexto histórico-social y no escapan a las influencias del mismo. Fue en la encrucijada de múltiples espacios donde construyó un conocimiento social: en la tesis que elaboró al culminar su carrera universitaria, como profesional al servicio del Estado, en sus investigaciones fisiológicas y en la Revista Educación Física. Sus producciones estuvieron impregnadas por las ideas positivistas y nacieron en la confluencia de los campos disciplinares de la medicina y la pedagogía. La ciencia médica tuteló y vigiló la constitución de la educación física escolar y, en este sentido, el higienismo marcó la definición de los contenidos dictados en los cursos de formación de los futuros docentes de la asignatura. ${ }^{105}$

El adiestramiento corporal fue un instrumento utilizado en el marco de las estrategias biopolíticas de gestión, que buscó el control de los cuerpos para forjar trabajadores y madres

\footnotetext{
${ }^{104}$ Mariano Plotkin y Federico Neiburg. Intelectuales y expertos...; Mariano Plotkin y Eduardo Zimmermann. Los saberes del...

${ }^{105}$ Scharagrodsky, Pablo. "El discurso médico...
} 
sanas, aptos para la producción y reproducción social. La intervención de Romero Brest buscó resolver problemáticas que encontró en las instituciones educativas; sin embargo, los saberes que generó trascendieron el ámbito institucional de actuación y definieron las políticas estatales. 